\title{
Karakteristik Wisatawan Pada Program City Tour Kota Denpasar
}

\author{
A.A. Surya Brahmana Putraa, 1, Ida Bagus Suryawana, 2 \\ 1agungsuryabp@gmail.com, ${ }^{2}$ idabagussuryawan@unud.ac.id \\ a Program Studi S1 Destinasi Pariwisata, Fakultas Pariwisata,Universitas Udayana, Jl. Dr. R. Goris, Denpasar, Bali 80232 Indonesia
}

\begin{abstract}
Denpasar Heritage City Tour is a recreation program based in Denpasar. This program was set to adjust the number of tourists to the city of Denpasar in particular. In the implementation of this program is still not very well known and used by tourists, but this program has run better. This study aims to find out how the tourism city of Denpasar and the characteristics of users of city tour program.

Collection data of this study techniques are observation, in-depth interviews, documentation studies and questionnaires. The thechnique of data analysist was used in this research by qualitative data analysis. This data indicate that it focus to the tourism in the city of Denpasar at this time and the questionnaire's result was choosen and calculated to determine the characteristics of tourists using the City Tour package.

This study's result has indicated that the tourists characteristic of program city tour by sex, tourists City Tour dominated by women, according to the age of tourists on the City Tour package users dominated 31-40 years old, according to the origin of the user City Tour package users in the dominance of the Asian continent, according to the tourist status of the City Tour user is dominated by married couples, depends on the level of education of the last tourists City Tour users dominated by scholars, according to monthly income Tourist Tour Tour dominated tourist income an average of 4 million and above and according to work User City Tour is dominated by private employees.

Keywords: Tourism Denpasar, City Tour Program
\end{abstract}

\section{PENDAHULUAN}

Bali merupakan pulau yang sangat identik dengan pariwisatanya dimana saat ini kata Bali dan Pariwisata merupakan kata yang saling berkaitan, dimana Bali juga memiliki julukan sebagai Pulau seribu Pura yang saat ini sudah dikenal hingga ke Eropa." Pulau Bali dikenal sebagai pulau "surga pariwisata" skala nasional di dunia, Bali juga dikenal denga Pulau seribu pura dan terkenal akan tradisi dan budayanya.

Bali yang memiliki beragam kebudayaan yang terdapat pada setiap kabupatennya, bila berbicara tentang Kota Denpasar, semua orang pasti berfikir Kota hanyalah tempak untuk bekerja saja atau hanya tempat untuk mencari nafkah dan bukanlah sebagai tempat untuk berekreasi.

Pemerintah Kota Denpasar membuat produk city tour yang menawarkan berbagai tempat-tempat yang masih memiliki unsur sejarah dan kebudayaan yang kental di Kota Denpasar diantaranya berupa puri, pura-pura, tempat yang bersejarah, dan pasar tradisional yang memiliki beragam jenis makanan tradisional serta DTW pariwisata lainnya (denpasarkota.go.id). Dimana pada dasarnya Program City Tour Kota Denpasar ini adalah program pengembangan pariwisata berbasis wilayah perkotaan di Kota Denpasar.

Denpasar Heritage City Tour ini hingga saat ini belumlah berjalan dengan baik, dimana belum banyak wisatawan yang mengetahui program city tour. Penelitian ini mengkaji tentang karakteristik wisatawan yang menggunakan program city tour Kota Denpasar, penelitian ini penting dilakukan guna melihat karakter wisatawan yang berkunjung pada program City Tour dan sebagai acuan pemerintah untuk mencari target pasar untuk program City Tour kedepannya.

\section{KEPUSTAKAAN}

Tinjauan hasil penelitian sebelumnya merupakan acuan yang digunakan sebagai perbandingan dengan penelitian yang akan dilakukan. Acuan tersebut berupa hasil dari penelitian sebelumnya dengan lokus maupun focus yang sama, sehingga mampu memperoleh gambaran awal terkait penelitian yang akan dilakukan memang penting untuk dilakukan. Berikut merupakan penelitian yang digunakan sebagai tinjauan pada penelitian ini Dalam skripsi ini dijelaskan mengenai bagaimana dasar Hukum dan Kebijakan City Tour di Kota Denpasar, apa saja Potensi yang dimiliki Kota Denpasar untuk mengaplikasikan paket City Tour serta bagaimana mewujudkan paket City Tour Kota Denpasar sebagai Program pariwisata. Persamaan penelitian ini adalah sama-sama berlokasi di Kota Denpasar, namun perbedaannya penelitian ini mengambil fokus tentang perbandingan Wisatawan pengguna paket City Tour dan Non City Tour, (Libhi, 2016) 
Penelitian selanjutnya ialah Penelitian ini juga menggunakan refrensi dari jurnal Internasional yang mengkaji tentang dampak Pariwisata yang terdiri dari dampak sosial, budaya dan lingkungan dan mengkomper pada metode yang digunakan yaitu Cost-Benefit Analysis tentang kekuatan dan kelemahannya,dan berikut penjelasan terkait penelitian seperti dapat dilihat dengan analisis biaya-manfaat seseorang dapat mengamati ketiga dampak, ekonomi, sosial budaya dan lingkungan (Djurasevic, 2007). Dalam rangka untuk membuat perbandingan, atau untuk menemukan persamaan dan perbedaan dengan menggunakan metode ini pada dampak yang berbeda, kita akan mengambil contoh program sosial-budaya untuk pariwisata di Zanzibar (Inskeep, 1991). Kesamaan penelitian terletak pada focus penelitian sama-sama mengambil focus pada komparasi.

Dalam artikel City Tour menggunakan beberapa konsep diantaranya:

\section{Konsep wisata perkotaan}

Inskeep (1991: 163) pariwisata perkotaan, bentuk pariwisata yang sangat umum terjadi di kota-kota besar di mana pariwisata bukan merupakan kegiatan utama dari daerah perkotaan yang biasanya berorientasi pada fitur daya tarik tertentu seperti ski salju, pantai, danau, dan rekreasi laut, fasilitas spa, pemandangan gunung, iklim gurun, situs arkeologi dan sejarah penting, dan agama ziarah. Dalam penelitian ini konsep wisata perkotaan digunakan untuk menegaskan deskripsi dari wisata kota.

\section{Karakteristik Wisatawan}

Karakteristik wisatawan dapat dibedakan kedalam dua jenis, "yaitu karakteristik sosial-ekonomi dan karakteristik perjalanan wisata" Smith (1989:13) dan terdapat 7 karakteristik wisatawan. Konsep karakteristik ini digunakan sebagai pedoman dalam melihat karakteristik wisatawan pengguna program city tour.

\section{METODE PENELITIAN}

Lokasi Penelitian ini dilakukan di Kota Denpasar Khususnya di Daya Tarik city tour Kota Denpasar. Sedangkan batasan untuk permasalahan meliputi kondisi eksisting kepariwisataan Kota Denpasar dan Setelah diketahui bagaimana gambaran umum terkait City Tour di Kota Denpasar bagaimana karakteristik wisatawan City Tour Kota Denpasar.

Sumber data yang digunakan dalam penelitian ini ialah data primer, yang berupa hasil wawancara dengan Kabid Pengembangan Destinasi Pariwisata Kota Denpasar terkait City Tour. Dan data sekunder meliputi kunjungan wisatawan ke daya tarik program city tour. Teknik pengumpulan data dilakukan dengan observasi ke lapangan untuk survei langsung ke daya tarik program city tour dan ke dinas Kota Denpasar untuk memperoleh kondisi eksisting Kota Denpasar, wawancara mendalam dengan narasumber secara langsung untuk mendapatkan informasi yang akurat mengenai City Tour Kota Denpasar.

Teknik penentuan sampel yang digunakan Dalam Penelitian ini yaitu tingkat kunjungan wisatawan selama satu bulan yang ada di objek wisata City tour dimana objek yang digunakan adalah Pasar Badung (1.710 orang), Pasar Kumbasari (1.133 orang) dan Museum Bali (3.713 orang). Sebelum menentukan metode pengambilan sampel, peneliti merumuskan terlebih dahulu jumlah sampel yang akan di gunakan. Teknik ini disebut dengan teknik penentuan sampel. Adapun jumlah sampel dalam penelitian ini ditentukan dengan menggunakan rumus slovin (sekaran, 2006)

Dalam penelitian ini peneliti menggunakan teknik penentuan informan menurut Koentjaraningrat (1993) dengan cara seleksi individu yang mengandalkan Informan Pangkal dan Informan Kunci, dimana peneliti mencari menentukan informan pangkal yang memiliki pengetahuan yang luas mengenai berbagai sektor di dalam masyarakatnya.Dimana informan pangkal pada penelitian kali ini adalah Kepala Dinas Pariwisata Kota Denpasar, kemudian mengarah kepada Kepala Pengelola Museum Bali serta yang terakhir wisatawan yang berkunjung ke Museum Bali.

Teknik analisis data Menurut Bogdan dan Biklen (1992) dalam Moleong (2012) "analisis data kualitatif. Teknik analisis data kualitatif dalam penelitian ini berupa gambaran rencana program City Tour Kota Denpasar sebagai produk pariwisata, serta perbandingan karakteristik wisatawan yang berkunjung pada DTW yang ada pada program City Tour Kota Denpasar. 


\section{HASIL DAN PEMBAHASAN}

\subsection{Gambaran Umum}

Gambaran umum dalam sub bab ini adalah gambaran Kota Denpasar yang menerapkan program City Tour. Dalam gambaran umum ini akan dijelaskan mengenai gambaran umum Kota Denpasar, gambaran umum pariwisata Kota Denpasar.

\subsubsection{Gambaran Umum Kota Denpasar}

Berdasarkan keputusan undang-undang nomor 32 tahun 2004 secara Administratif, Pemerintah Kota Denpasar memiliki 4 wilayah yang diresmikan pada tanggal 27 Februari 1992. Kota Denpasar merupakan wilayah termuda di Bali, berdasarkan dokumen "Data Pariwisata Kota Denpasar Tahun 2015" yang menjelaskan bahwa secara historis awalnya merupakan pusat Kerajaan Badung dan bagian dari Kabupaten Badung

Awal mula Kota Denpasar merupakan pusatnya kegiatan atau aktivitas pada masa Kerajaan Badung, pada tahun 1985 dan seiring berjalannya waktu pemerintahan tersebut mulai dijadikan pusat pemerintahan Provinsi daerah tingkat I Bali dari tingkat II. Perkembangan fisik, ekonomi maupun sosial budaya bergerak sangat pesat dan menjadi lebih baik sehingga Kota Denpasar dijadikan sebagai pemerintahan pusat sebagai alur perdagangan, pendidikan, industry serta pariwisata. Sama dengan kota - kota lainnya di Negara Indonesia, Denpasar yang merupakan Ibukota di Provinsi Bali memiliki perkembangan penduduk yang sangat pesat serya seluruh aspek dari Kota Denpasar yang terus mangalami peningkatan dan memberikan dampak bagi Kota Denpasar.

\subsubsection{Gambaran Umum Pariwisata Kota Denpasar}

Berdasarkan dokumen "Data Pariwisata Kota Denpasar 2015" juga menjelaskan tentang kepariwisataan Kota Denpasar yang mengalami perkembangan yang cukup signifikan di tengahtengah isu global yang cenderung menurun. "Mengingat semakin ketatnya persaingan industri pariwisata di dunia, Kota Denpasar diharapkan mampu mempertahankan posisinya menjadikannya bagian dari destinasi wisata unggulan di Pulau Bali. Sebagai daerah tujuan wisata, Kota Denpasar berada dilokasi yang cukup strategis karena berada di pusatnya kegiatan dan aktivitas di Pulau Bali serta dikelilingi dengan berbagai destinasi maupun daya tarik pendukung lainnya.

\section{Kepariwisataan Kota Denpasar}

Kepariwisataan Kota Denpasar saat ini bisa dikatakan sudah mengalami peningkatan setiap tahunnya berdasarkan data pada buku " Data Pariwisata Kota Denpasar Tahun 2015", Peningkatan yang dialami berdasarkan data yang di peroleh sejak tahun 2011 hingga 2015, mengamati segmentasi pasar di Kota Denpasar sepanjang tahun 2014 dan 2015, kunjungan wisatawan yang berasal dari pasar Asia di dominasi dari Negara Cina, Jepang dan Korea Selatan sedangkan segmentasi pasar yang berasal dari benua Eropa di dominasi dari Negara Belanda, perancis, Jerman, Amerika, Inggris dan Denmark. Sementara kunjungan wisatawan terbesar ke Kota Denpasar tahun 2015 berasal dari Negara Cina dengan jumlah kunjungan 56,416 orang.

Sejak di tetapkannya program City Tour oleh Pemerintah Kota Denpasar yang sudah berjalan selama 2 tahun yang pertama di mulai dari Museum Bali, Pura Jagatnatha, Puri Jero Kuta, Pura Moaspahit, Pasar Badung dan yang terakhir di Hotel Inna Bali. Menurut penjelasan Kepala Bidang Pengembangan Destinasi Pariwisata Bapak Made Sudira memaparkan:

" Kepariwisataan di Kota Denpasar ini tidak berkembang dengan mulus, dimana dulu Denpasar ingin mengembangkan City Tour yang bekerjasama denga HPI (Himpunan Pramuwisata Indonesia) yang berjanji akan mendatangkan wisatawan ke objekobjek yang ada tetapi tidak berjalan sukses, dan Denpasar terus berusaha untuk membangkitkan City Tour akan tetapi hingga saat ini Program City Tour belum berkembang secara maksimal. Peningkatan kunjungan ada namun belum maksimal dikarenakan tamu yang berkunjung tidak semuanya melapor ke Dinas hanya tamu yang rombongan yang menggunakan bus saja yang melapor, tamu individu mereka langsung datang ke objek tanpa melapor maka dari itu kami kesulitan untuk memantau". 
Berdasarkan pemaparan diatas kondisi kepariwisataan kota Denpasar dan sejak di tetapkannya Program City Tour pada tahun 2015 keduanya sudah mengalami perkembangan namun belum maksimal, hingga saat ini Dinas Pariwisata Kota Denpasar terus berbenah dan saat ini sedang dilakukan penggarapan terkat pusat informasi terkait City Tour yang akan di letakkan pada gedung Dinas Pariwisata lama yang terletak di sebelah utara Pura Jagat Natha.

\subsection{Karakteristik Wisatawan City tour Kota Denpasar}

Karakteristik wisatawan memiliki 7 bagian diantaranya adalah jenis kelamin, daerah asal, usia, pendidikan pekerjaan, status perkawinan, dan pendapatan.

Dalam menentukan sampel peneliti menggunakan acuan tingkat kunjungan wisatawan selama satu bulan yang ada di objek wisata City tour dimana objek yang digunakan adalah Pasar Badung (1.710), Pasar Kumbasari (1.133) dan Museum Bali (3.713). Sebelum menentukan metode pengambilan sampel, peneliti merumuskan terlebih dahulu jumlah sampel yang akan di gunakan. Teknik ini disebut dengan teknik penentuan sampel. Adapun jumlah sampel dalam penelitian ini ditentukan dengan menggunakan rumus slovin (sekaran, 2006) yakni :

$$
n=\frac{N}{1+N e^{2}}
$$

keterangan

$n=$ jumlah sampel

$\mathrm{N}=$ jumlah populasi

$\mathrm{e}=$ batas toleransi kesalahan (error tolerance)

Dalam penelitian ini, ukuran populasi mengacu pada jumlah kunjungan wisatawan di 3 objek wisata yang ada di paket City Tour yakni Pasar Badung, Pasar Kumbasari, Museum Bali yang di jumlahkan menjadi 6.556 dan di bagi 3 agar mendapatkan jumlah selama satu bulan menjadi 2186 dengan tingkat kesalahan 10\%. Berikut ini perhitungan dengan menggunakan rumus slovin :

$n=2186 / 1+2186(10 \%)^{2}$

$n=6.556 / 1+21,86$

$n=2186 / 22,86=95,62$ di bulatkan menjadi 96 sampel, 96 sampel ini dibagi 2 lagi karena hanya mencari perhitungan selama 2 minggu yang mendapatkan hasil menjadi 48 sampel, sampel dicari pada DTW city tour Kota
Denpasar. Wisatawan yang dianggap sebagai pengguna paket City Tour ialah yang minimal berkunjung pada 3 objek yang ada pada paket City Tour.

Tabel 4.1

Perbandingan Karakteristik wisatawan

\begin{tabular}{|c|c|c|}
\hline No & Karakteristik & Wisatawan City Tour \\
\hline \multirow[t]{3}{*}{1} & Jenis kelamin & \\
\hline & Laki - laki & 22 orang wisatawan \\
\hline & Perempuan & 24 orang wisatawan \\
\hline \multirow[t]{4}{*}{2} & Umur & \\
\hline & $20-30$ thn & 16 orang wisatawan \\
\hline & $31-40$ thn & 17 orang wisatawan \\
\hline & 40 thn $<$ & 15 orang wisatawan \\
\hline \multirow[t]{5}{*}{3} & Asal & \\
\hline & Eropa & 14 orang wisatawan \\
\hline & Asia & 28 orang wisatawan \\
\hline & Amerika & - \\
\hline & Australia & 6 orang wisatawan \\
\hline \multirow[t]{4}{*}{4} & Status & \\
\hline & Single & 16 orang wisatawan \\
\hline & Menikah & 32 orang wisatawan \\
\hline & Lainnya & - \\
\hline \multirow[t]{8}{*}{5} & $\begin{array}{l}\text { Pendidikan } \\
\text { Terakhir }\end{array}$ & \\
\hline & Tidak bersekolah & - \\
\hline & SD & - \\
\hline & SMP & - \\
\hline & SMA & 1 orang wisatawan \\
\hline & Diploma & - \\
\hline & Sarjana & 35 orang wisatawan \\
\hline & Lainnya & 12 orang wisatawan \\
\hline \multirow[t]{5}{*}{6} & $\begin{array}{l}\text { Pendapatan } \\
\text { Perbulan }\end{array}$ & \\
\hline & $<1$ juta & 6 orang wisatawan \\
\hline & 2 juta & - \\
\hline & 3 juta & 18 orang wisatawan \\
\hline & $>4$ juta & 24 orang wisatawan \\
\hline \multirow[t]{6}{*}{7} & Pekerjaan & \\
\hline & $\begin{array}{l}\text { Siswa/ } \\
\text { Mahasiswa }\end{array}$ & 4 orang wisatawan \\
\hline & PNS & 8 orang wisatawan \\
\hline & Pegawai Swasta & 16 orang wisatawan \\
\hline & Wiraswasta & 13 orang wisatawan \\
\hline & Ibu rumah tangga & 7 orang wisatawan \\
\hline
\end{tabular}

Sumber : Penelitian 2017

Menurut pemaparan Tabel 4.1 jenis kelamin wisatawan City Tour di dominasi oleh perempuan, menurut usia wisatawan pada pengguna paket City Tour didominasi usia 3140 tahun, menurut asal wisatawan pengguna paket City Tour di dominasi dari benua Asia 
yaitu jepang, menurut status wisatawan pengguna City Tour didominasi oleh pasangan menikah, menurut tingkat pendidikan terakhir wisatawan pengguna City Tour didominasi oleh sarjana, menurut pendapatan perbulan Wisatawan City Tour didominasi wisatawan berpenghasilan rata-rata 4 juta keatas dan menurut pekerjaan Pengguna City Tour didominasi oleh pegawai swasta. Pengguna paket City Tour didominasi oleh perempuan karena wisatawan yang berkunjung cenderung ibu dengan anak-anak perempuan, umur wisatawan didominasi oleh umur 31-40 karena wisatawan yang berkunjung cenderung wisatawan yang memiliki keingintahuan tentang sejarah dan kebudayaan yang ada di DTW City Tour Kota Denpasar, wisatawan yang datang cenderung berasal dari Negara Jepang dan cina, menurut status wisatawan didominasi oleh pasangan yang sedang berlibur sembari membawa anak-anak, berdasarkan tingkat pendidikan wisatawan di dominasi oleh sarjana karena sebagian besar merupakan wisatawan yang berkunjung memiliki keingintahuan tentang kebudayaan dan nilai sejarah dari DTW City Tour Kota Denpasar, menurut penghasilah wisatawan yang dating rata-rata berpenghasilan 4 juta keatas dan dominan sebagai pegawai swasta dimana pegawai swasta memiliki gaji yang dominan besar.

\section{PENUTUP}

\subsection{Simpulan}

Kepariwisataan di Kota Denpasar saat ini sudah mengalami peningkatan namun belum berkembang dengan mulus, maka dari itu pemerintah terutama Dinas Pariwisata Kota Denpasar harus terus gencar dalam melakukan promosi dan pembenahan dalam meningkatkan kunjungan wisatawan ke Kota Denpasar. Setelah ditetapkannya program Heritage City Tour oleh Pemerintah Kota Denpasar tahun 2015 lalu tingkat kunjungan wisatawan mulai meningkat secara perlahan. Karakteristik wisatawan program city tour menurut jenis kelamin, Pengguna paket City Tour didominasi oleh perempuan karena wisatawan yang berkunjung cenderung ibu dengan anak-anak perempuan, umur wisatawan didominasi oleh umur 31-40 karena wisatawan yang berkunjung cenderung wisatawan yang memiliki keingintahuan tentang sejarah dan kebudayaan yang ada di DTW City Tour Kota
Denpasar, wisatawan yang datang cenderung berasal dari Negara Jepang dan cina, menurut status wisatawan didominasi oleh pasangan yang sedang berlibur sembari membawa anakanak, berdasarkan tingkat pendidikan wisatawan di dominasi oleh sarjana karena sebagian besar merupakan wisatawan yang berkunjung memiliki keingintahuan tentang kebudayaan dan nilai sejarah dari DTW City Tour Kota Denpasar, menurut penghasilah wisatawan yang dating rata-rata berpenghasilan 4 juta keatas dan dominan sebagai pegawai swasta dimana pegawai swasta memiliki gaji yang dominan besar.

\subsection{Saran}

Pemerintah Kota Denpasar agar lebih menggencarkan promosi paket City Tour ini dan tetap melakukan pengawasan agar mengetahui seberapa jauh mengalami peningkatan atau penurunan, dan Pemerintah juga diharapkan bisa melakukan kerjasama yang lebih dengan para pelaku pariwisata yakni dengan Travel Agent agar paket City Tour ini dapat dinikmati oleh wisatawan dan dapat meningkatkan kunjungan wisatawan ke Kota Denpasar.

Pengelola setiap DTW city tour juga harus saling berkoordinasi dengan pemerintah Kota Denpasar khususnya dengan Dinas Pariwisata Kota Denpasar agar tetap bisa mengetahui seberapa besar tingkat pengguna program city tour Kota Denpasar.

\section{DAFTAR PUSTAKA}

Anonim Undang Undang No 10 Tahun 2009

Anonim Undang Undang No 22 Tahun 1999

Anonim Peraturan Pemerintah Nomor 19 Tahun 1995

Arikunto, S. 2010. Prosedur penelitian : Suatu Pendekatan Praktik. (Edisi Revisi). Jakarta : Rineka Cipt

Dinas Pariwisata Kota Denpasar, Denpasar Goverment Tourism Office Tahun 2015

Djurasevic, S., \& Nedelea, A. (2007).Comparing and contrasting the alternative methodologies available for evaluating the impact of tourism.

H.B. Sutopo.2006.Penelitian Kualitatif : Dasar Teori dan Terapannya Dalam Penelitian.Surakarta: Universitas Sebelas Maret.

Inskeep Edward. (1991). Tourism Planning An Integrated and Sustainable Development Approach. New York: Van Nostrand Reinhold.

Jurnal 2016, Pengemasan Paket Wisata City Tour Berbasis Budaya Di Kota Denpasar Bali, oleh I Wayan Gede Ary Mahendra Putra, I Made Kusuma Negara dan I Putu Sudana.

Koentjaraningrat.(1993). Metode-Metode Penelitian Masyarakat Edisi Ketiga.

Jakarta: Gramedia. 
Vol. 6 No 2, 2018

Kusmayadi dan Sugiarto, Endar. 2000, Metode Penelitian dalam Bidang Kepariwisataan,Jakarta: PT Gramedia Pusataka Utama.

Moh.Nazir.Ph.D, 2005, Metode Penelitian.Ghalia Indonesia. Bogor.

Sekaran, Uma. 2006. Metodologi penelitian untuk bisnis, Salemba Empat. Jakarta

Sekaran, Uma. 2011. Research Methods for business Edisi I and 2. Jakarta: Salemba Empat.

Skirpsi 2016, Rencana Program City Tour Kota Denpasar Sebagai Produk Pariwisata, oleh Kadek Sidhi Surya Libhi.

Smith, S.L.J. and D. Stephen. 1989. Tourism Analysis: A Han dbook. Longman Scientific \& Technical. New York

Soekadijo. 2000.Anatomi Pariwista.Jakarta : Gramedia.

Spillane, James, J, 1994. Pariwisata Indonesia : Siasat Ekonomi dan Rekayasa Kebudayaan. Kanisius. Yogyakarta

Sugiyono, (2008).Metode Penelitian Kunatitatif Kualitatif dan R\&D.

Bandung Alfabet

Sugiyono.2012. Metode Penelitian Kuantitatif Kualitatif dan R\&B.

Bandung: Alfabeta.

Sugiyono.2013.Metode Penelitian Pendidikan.Pendekatan Kuantitatif, Kualitatif, dan R\&D. Bandung:Alfabeta

Suwantoro, Gamal. 1997.Dasar-Dasar Pariwisata. Yogyakarta: Andi Yogyakarta.

Sumber lain :

Encarta Researcher,

2003.http://globallavebookx.blogspot.co.id/201

4/02/pengertian-museummenurut-para-

ahli.html (23 maret 2017). 10.41

http://www.wisatakandi.com/2011/11/undang-undangri-no-10-tahun-2009.html (4mei 2017) 12.23

http://www.kemenpar.go.id/userfiles/file/4552_1360PengelolaanKoleksi.pdf (4mei 2017) 01.01 